\title{
Air borne pollen of Parthenium hysterophorus in Parbhani ${ }^{*}$ Rajkumar H. Thorat and S.G. Pillai ${ }^{1}$
}

\author{
*Yogeshwari College AMBAJOGAI (MS) INDIA, \\ ${ }^{1}$ Shri Shivaji College PARBHANI (MS) INDIA \\ ${ }^{*}$ Corresponding Author \\ Email: - thoratrh@gmail.com
}

\author{
Received : 04.09.2019; Accepted : 04.11.2019
}

\begin{abstract}
Aeropalynology is most important branch for study of pollen distribution in air and also to know effect of pollens on human. An aeropalynological investigation was carried out at various localities of Ambajogai. The survey was performed by using Rotorod air Sampler for 3 months (June, July, \& August) for two years 2009 \& 2010.Among other pollen, pollen resembling echinulate Asteraceae type were trapped. After Systematic Identification, it was found that the pollen belongs to Parthenium hysterophorus.

Figure : 00

References : 04

Table : 01

KEY WORDS : Echinulate, Parthenium hysterophorus, Rotorod air sampler,
\end{abstract}

\section{Introduction}

It is known that the incidence of allergic disorders in the human system may be a result of airborne pollen inhalation originating from allergenically significant plants. A detailed record of the flowering periodicity in a particular area facilitates aerobiological investigations.

Correct identification and nomenclature of a species are mandatory, without which it may be misleading for environmentalists, aerobiologists, conservationists and also taxonomists.

Parthenium hysterophorus is a weed that was imported into India along with the PL 480 Mexican wheat seeds in the 50s. The weed has since grown into uncontrollable proportions invading million of hectares of uncultivated wastelands, roadsides, railway tracks, etc. The fast growing weed is a nuisance in public parks, residential colonies and orchards.

Not only that, it causes health hazards such as skin allergy, hay fever and asthma in human beings and is toxic to livestock. It squeezes grasslands and pastures, reducing the fodder supply. Scientists describe it as a "poisonous, allergic and aggressive weed posing a serious threat to human beings and livestock. ${ }^{3}$

Parthenium hysterophorus (Asteraceae) pollen of this species are known to cause allergic reaction and have posed serious public health hazard during the past several years in the areas where this weed grows.

The presence of parthenium in cropped lands results in yield reduction upto 40 percent. The pollen grains inhibit fruit set in tomato, brinjal, beans, etc. It is also responsible for bitter milk disease in livestock fed on grass mixed with parthenium.

Contact with this plant causes dermatitis and respiratory malfunction in humans, dermatitis in cattle and domestic animals, due to the presence of toxin Parthenin.

\section{Materials and Methods}

Rotorod air sampler was employed to sample air ,twice every day in the morning 10.00 am to $10.30 \mathrm{am}$ and in the evening 4.00 to $4.30 \mathrm{pm}$ for the period of 3 months (June, July, August) for two years i.e. 2009 and 2010. Collections were made with the sampler upright on the stool approximately 18 inches above the ground. The slides prepared from the rotorod Sampler were scanned with the help of reference slides. Allergic aspect was carried with the help of allergy clinics.

\section{Results and Discussion}

From June to August 2009 \& 2010 a number of pollen were identified as Parthenium type representing about $80-90 \%$ of the total catches during these months. The author tried to identify these pollen to the specific level on the basis of source slides but their identification was dubious till the plant specimens were finally identified as Parthenium hysterophorus. This identification highlights its distribution. The other pollen were of the Asteraceae, Populus, Platanus.Poaceae and Aesculus types.

In addition to this pollen, Fungal spores, filaments, insect parts ,trichomes and some unidentified pollen grains were also observed (Table-1). 
TABLE-1 : Airspora in Parbhani area

\begin{tabular}{|l|c|c|c|c|c|c|}
\hline & \multicolumn{2}{|c|}{ June } & \multicolumn{2}{c|}{ July } & \multicolumn{2}{c|}{ August } \\
\cline { 2 - 7 } & $\mathbf{2 0 0 9}$ & $\mathbf{2 0 1 0}$ & $\mathbf{2 0 0 9}$ & $\mathbf{2 0 1 0}$ & $\mathbf{2 0 0 9}$ & $\mathbf{2 0 1 0}$ \\
\hline Parthenium Hysterophorus & 173 & 183 & 222 & 208 & 192 & 315 \\
\hline Asteraceae & 8 & 10 & 7 & 5 & 5 & 5 \\
\hline Platanus & 11 & 9 & 8 & 4 & 6 & 7 \\
\hline Populus & 9 & 8 & 3 & 2 & 0 & 1 \\
\hline Poaceae & 14 & 9 & 12 & 11 & 7 & 5 \\
\hline Unidentified Pollen & 3 & 8 & 8 & 3 & 5 & 5 \\
\hline Fungal spores & 8 & 7 & 10 & 10 & 14 & 12 \\
\hline Filaments & 3 & 2 & 2 & 1 & 1 & 2 \\
\hline Trichomes & 3 & 3 & 2 & 3 & 4 & 5 \\
\hline
\end{tabular}

Parthenium pollen appeared throughout the period of investigation with a major peak in August. Its occurrence has been reported throughout the year in other parts of the country ${ }^{1-3}$.

When pollen of Parthenium comes in contact with the skin of humans and also some pet animals, skin cracks and sores develop due to which the skin becomes very hard, like that of a crocodile ${ }^{4}$ and such allergic disorders were commonly seen in the surveyed areas. The same disorder was also observed when the tests were performed in two different laboratories.

Nasal inhalation tests were performed and respiratory sounds, air flow measurements as well as visual symptoms assessed at the two laboratories. After compiling all the observations, it was concluded that such pollen also causes throat and skin irritation, particularly during the season when the pollen concentration is very high.

\section{Conclusion}

The results obtained during the months of the year 2009 \& 2010 show that the shift in the wind pattern has not caused any change in the composition of air borne pollen assemblages. All the spectra mainly reflect the surrounding vegetation

\section{References}

1. $\quad$ Agashe SN, Abraham JN.Pollen calendar of Bangalore city:Part-I.-Indian Journal of Aerobiology 1988; 1(1):3538.

2. Chanda S, Nandi NC.A preliminary report on the aerobiology of greater Caluctta.-Asp.Aller.and App. Immun. 1971; 5:128-134.

3. Singh AB. Gangal SV. Sampling and distribution pattern of allergenic biopollutants in atmosphere. Biological Memoirs. 1986; 12:114-122.

4. Stanley RG, Linsken HF.Pollen:Biology,Biochemistry and Management.-Springer-verlag,Berlin. 1974. 